\title{
Comparative study of bupivacaine plus xylocaine with adrenaline versus bupivacaine plus xylocaine with adrenaline plus fentanyl in intrapleural block for post operative analgesia for modified radical mastectomy cases
}

Krunal P. Ramteke ${ }^{1 *}$, Vrinda A. Oza ${ }^{2}$, Vandana S. Parmar ${ }^{3}$ and Srividya Peram ${ }^{4}$

*Correspondence: krunal.ramteke24@gmail.com

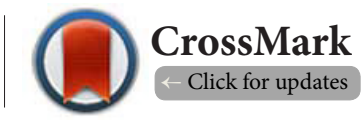

\begin{abstract}
13rd year Resident, Department of Anaesthesiology, Pandit Deendayal Upadhyay Medical College, Rajkot, Gujarat. ${ }^{2}$ Assistant Professor, Department of Anaesthesiology, Pandit Deendayal Upadhyay Medical College, Rajkot, Gujarat. ${ }^{3}$ Professor and head, Department of Anaesthesiology, Pandit Deendayal Upadhyay Medical College, Rajkot, Gujarat. ${ }^{4} 2$ nd Year resident, Department of Anaesthesiology, Pandit Deendayal Upadhyay Medical College, Rajkot, Gujarat.
\end{abstract}

\begin{abstract}
Background: Postoperative pain plays a significant role in the pathogenesis of postoperative pulmonary complications after upper abdominal and thoracic opera $\neg$ tions. Diminishing lung volumes due to acute restrictive pulmonary dysfunction due to pain may result in relative hypoxemia, major atelectasis and pulmonary consolidation. Intrapleural analgesia is one of the method for postoperative analgesia.

Methods and Material: After clearance from Institutional Ethics Committee, 80 patients undergoing modified radical mastectomy were selected and divided into two groups randomly. Group B: Intrapleural block was given with inj. Bupivacaine $0.5 \%(20 \mathrm{ml})$ with xylocaine adrenaline 10ml. Group BF: Block was given with Bupivacaine $0.5 \%(20 \mathrm{ml})$ with xylocaine adrenaline $10 \mathrm{ml}$ with inj. Fentanyl $1 \mathrm{mcg} / \mathrm{kg}$. Total duration of sensory block and analgesia, intraoperative hemodynamics, postoperative pain score and lung volumes and requirement of rescue analgesics were observed.

Results: Hemodynamic parameters were comparable in both the groups. Onset of sensory block in

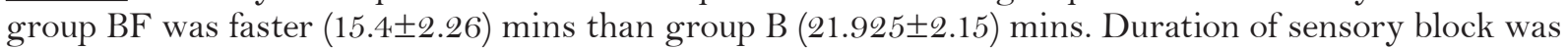
significantly higher in group BF $(6.45 \pm 1.13)$ hrs than group B (3.5125 \pm 0.51$)$ hrs. Total analgesia was significantly prolonged in group BF (11.3 $\pm 1.0024 \mathrm{hrs})$ than group B $(7.33 \pm 2.0153 \mathrm{hrs})$. Requirement of rescue analgesic dose in group BF was lower (2.05 \pm 0.67$)$ than group B (3.025 \pm 0.69$)$ Better preservation and earlier recovery of respiratory volumes noted in group BF.

Conclusions: Intrapleural block given with local anaesthetic and fentanyl had faster onset and longer duration of sensory blockade with better preservation of lung volumes.

Keywords: Intrapleural block, , Modified Radical Mastectomy,, Post operative analgesia., regional block

Effective postoperative analgesia is a very essential component of the care of the surgical patient. Inadequate pain controlmay result in increased rate of morbidity or mortality. Evidence suggests that surgery suppresses the immune system proportionate to the invasiveness of the surgery. Good analgesia can effectively reduce this deleterious effect. Various studies available indicate that afferent neural blockade with the help of local anaesthetics is the most effective a technique of analgesia. The advantages

of effective postoperative pain management include patient comfort and therefore satisfaction, earlier mobilization, reduced pulmonary and cardiac complications, a lowered risk of deep vein thrombosis, faster recovery with less likelihood of the development of neuropathic pain, and reduced cost of care [1].

The adverse sequels of postoperative pain are numerous. Patients with significant postoperative pain may demonstrate anxiety, fright, insomnia which often exacerbate their pain perception rendering the postoperative recovery period an
\end{abstract}

\section{Introduction}

(C) 2019 Ramteke et al; licensee Herbert Publications Ltd. This is an Open Access article distributed under the terms of Creative Commons Attribution License (http://creativecommons.org/licenses/by/3.0). This permits unrestricted use, distribution, and reproduction in any medium, provided the original work is properly cited. 
unpleasant and ominous experience. Other pain related stress responses include coagulation system activation, aggregation of platlets and fibrinolytic system alteration which may increase clotting leading to deep venous thrombosis and pulmonary embolism. Pain increases the sympatho-adrenal outflow of catecholamines leading to dysrhythmias, tachycardia and hypertension.

Postoperative pain is one of the major factor in postoperative pulmonary complication especially after upper abdominal and thoracic operations. Reduction of lung volumes due to acute restrictive pulmonary dysfunction secondary to pain may result in relative hypoxemia, major atelectasis and pulmonary consolidation.

Breast cancer surgeries are commonly performed under general anaesthesia which is the standard technique, but is associated with acute post-operative pain further aggravated by the arm and shoulder movements $[2,3]$. Concomitant use of regional blocks can not only help to minimize pain, but also improves the pulmonary function and reduce narcotic requirement during the perioperative period $[4,5]$.

Among the regional techniques such as intercostal nerve block, thoracic epidural, thoracic paravertebral block (PVB), and inter pleural block (IPB), the last two are commonly being used to provide intra and post-operative analgesia in patient undergoing modified radical mastectomy $[6,7]$. Perioperative hypertension, tachycardia, headache, nausea, vomiting, and pain are frequently seen following breast surgery. This pain restricts shoulder movement postoperatively and may not be responding except for parenteral narcotics that have an emetogenic effect that needs further observation of these patients [8]. It is widely assumed that when postoperative patients are relatively pain free, their pulmonary functions are improved [9].

Intrapleural regional analgesia is a method of postoperative pain relief reported by Reiestad and Stromskug [10]. This technique provides a unique form of regional analgesia that has proven advantageous for upper abdominal surgical interventions and breast surgeries.

\section{Subjects and Methods}

After clearance from Institutional Ethics Committee, the study was carried out in patients undergoing Modified Radical Mastectomy (MRM). It was a randomized prospective double blind study. The observer and the patient were blinded for the study drug.

After careful pre-anaesthetic evaluation, 80 female patients diagnosed with Carcinoma of Breast in the age group of 20-69 years, American Society of Anaesthesiologist (ASA) physical status I, II or III who required MRM were included in the study.

\section{Inclusion criteria}

All the cases undergoing radical mastectomy of ASA grade I, II, III.

\section{Exclusion citeria}

- Coagulation abnormalities
Known Allergy reaction to drug

Patient refusal

Systemic sepsis or local infection at the puncture point

Thoracic infection within the past 3 months.

- Patients with emphysema and chronic obstructive pulmonary disease (as these respiratory pathologies may have hyper inflated lungs with air filled bullae, injury to which may be difficult to predict and prevent complications).

\section{- Previous or planned pleurectomy}

Informed consent for General anaesthesia as well as Intrapleural block (IPB) was obtained from the patients and care takers in the prescribed format. The patients were randomly allocated into two groups by computer generated random number sequence in 40 patients each. Odd numbers were given to group $B$ (control group) and the even numbers were given to Group BF.

\section{Group B: Control group}

Intrapleural block was given with Inj Bupivacaine 0.5\% (20 ml) with xylocaine adrenaline (1:200000) $10 \mathrm{ml}$ and $5 \mathrm{ml} 0.9 \%$ saline.

\section{Group BF: Study group}

Intrapleural block was given with Inj. Bupivacaine 0.5\% (20 $\mathrm{ml}$ ) with xylocaine adrenaline $(1: 200000) 10 \mathrm{ml}$ and $5 \mathrm{ml}$ saline $0.9 \%$ with inj. Fentanyl 1 microgram $/ \mathrm{kg}$.

In this study, we use a posterior approach for giving interpleural block and perform injections with the patient in lateral position with affected side upwards before giving general anaesthesia. Consent for the procedure was obtained as per Institution protocol. The block was performed inside the Operation Theatre with an appropriate area which offered privacy, good lighting and ensures sterility, and with oxygen, monitoring and resuscitation drugs and equipment availablereadily. A senior anaesthetic assistant was always present to watch for procedure and full aseptic precautions observed (Photos 1-3).

\section{The following parameters were noted}

1. Time taken for onset of sensory blockade

2. Maximum level of sensory blockade attained

3. Intraoperative Hemodynamics.

4. Duration of sensory block

5. Duration of analgesia

6. Postoperative sedation

7. Postoperative pain score- Verbal Rating Scale (VRS) and Visual Analog Scale (VAS).

8. Postoperative Lung volumes and Peak Expiratory Flow Rate (PEFR)

9. No. of rescue analgesia required in 24 hours.

10. Adverse effects

Onset of sensory blockade was taken as a time taken from the complete injection of study drug till the patient does not feel the pin prick at T4 level.

Duration of analgesia was considered as the time taken 

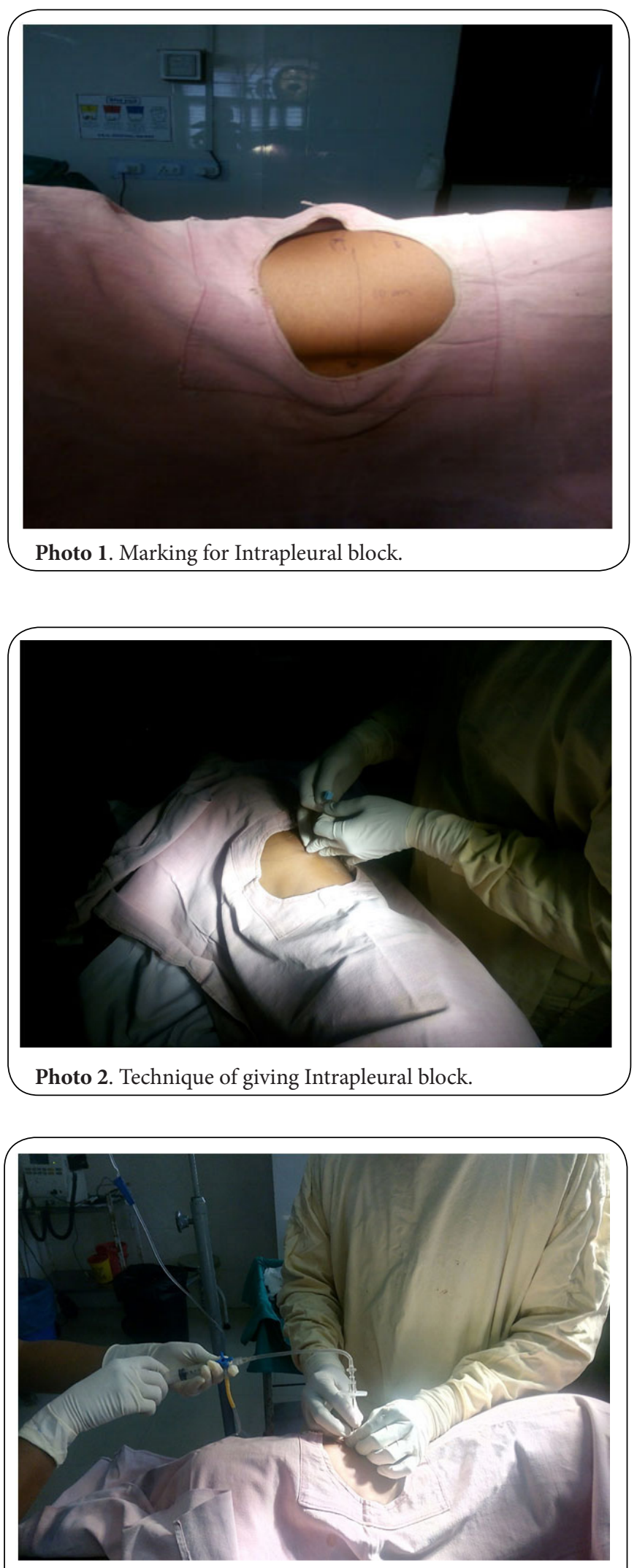

Photo 3. Confirmation of intrapleural space and administration of drugs. from the completion of the injection of the study drug till the patient requests for analgesic in the post-operative period. Intravenous Diclofenac sodium $75 \mathrm{mg}$ was given as the rescue analgesic if the VAS pain score was $\geq 4$. Same dose was repeated whenever patient complained pain afterwards and number of doses counted for 24 hours.

\section{Statistical analysis}

Data analysis has been done using the Microsoft excel software 2007.

Sample size was calculated on assuming $80 \%$ statistical power and 5\% a error. Sample size calculation was based on the presumption that post-operative requirement of inj. Diclofenac sodium as an analgesic drug as per VAS score and VRS taking the difference of $50 \mathrm{mg}$ [among the total requirement] in 24 hours in both the group as (d) and Standard Deviation was taken 76.8 from the previous study. Considering dropouts total 40 patients in each group will be enrolled.

An unpaired t test was used to compare demographic variables, intra operative hemodynamic variables (heart rate, systolic blood pressure) oxygen saturation, and onset and duration of sensory and motor block between the groups. Sedation scores and pain scores were compared, while rescue analgesic requirements in both groups were compared by $\mathrm{Chi}$ square test. Inspiratory reserve volume, expiratory reserve volume, tidal volume and peak expiratory flow rate (PEFR) were also assessed. Intergroup comparison was done, using unpaired " $\mathrm{t}$ "Test and comparing mean and standard deviation.

$A$ " $p$ " value $<0.05$ was taken as significant and " $p$ " value $<0.001$ was taken as highly significant. All the values were presented as Mean \pm SD. Confidence Interval were calculated using Microsoft excel software 2007.

\section{Results}

Eighty patients were recruited. All the patients underwent radical mastectomy and received their allocated study drug. No assigned patients dropped out of the study. Demographic profile and surgical data were statistically comparable in both the groups (Tables 1 and 2). Mean Arterial pressure in group $B$ and group BF before and after giving intrapleural block as well as intraoperatively and postoperatively were recorded. There were no statistical significant difference in both the groups throughout the procedure (Figure 1). Mean time of onset of sensory block in group B was higher (21.925 \pm 2.15 minutes) than in group $B F(15.4 \pm 2.26$ minutes) which was statistically significant $\{p<0.01\}$ (Figure 2). Confidence interval of $95 \%$ cases of Group B is 22.592 to 21.258 min and Group BF is 16.10 to $14.69 \mathrm{~min}$. Mean duration of sensory block in group $B$ was $3.5125 \pm 0.51$ hours and in group BF it was $6.45 \pm 1.13$ hours which was significantly higher $\{p<0.01\}$ in group $B F$ than group B (Figure 3). Confidence interval of $95 \%$ cases of Group B is 7.95 to 6.70 hours and Group BF is 11.61 to 10.99 hours. Mean duration of analgesia was significantly higher in group BF ( $11.3 \pm 1.00$ hours) than group B (7.95 to 6.70 hours) 
Table 1. Patient characteristics and operative data.

Data expressed as Mean (SD).

\begin{tabular}{llll}
\hline & $\begin{array}{l}\text { Group B } \\
\mathbf{n = 4 0}\end{array}$ & $\begin{array}{l}\text { Group BF } \\
\mathbf{n = 4 0}\end{array}$ & P value \\
\hline Age (years) & $46 \pm 8.75$ & $47.95 \pm 7.98$ & 0.30 \\
Weight (kg) & $58.8 \pm 5.78$ & $59.77 \pm 7.17$ & 0.79 \\
$\begin{array}{l}\text { Duration of Surgery } \\
\text { (minutes) }\end{array}$ & $127.25 \pm 21.15$ & $122.62 \pm 21.18$ & 0.33 \\
ASA Status & I/ II/ III & I/ II/ III & -- \\
\hline
\end{tabular}

Table 2. Complications noted during the procedure and postoperatively.

\begin{tabular}{lll}
\hline Complication & Group B & Group BF \\
\hline Nausea-vomiting & 2 & 3 \\
Chest pain & 2 & 1 \\
Coughing & 5 & 4 \\
Convulsions & 0 & 0 \\
Hypotension & 0 & 0 \\
Bradycardia & 0 & 0 \\
Pneumothorax & 0 & 0 \\
Respiratory depression & 0 & 0 \\
Pruritus & 0 & 2 \\
\hline
\end{tabular}

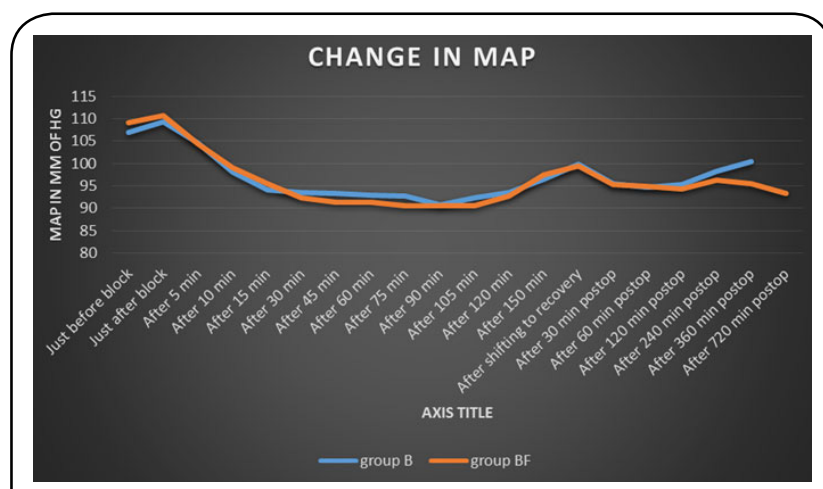

Figure 1. Changes in mean arterial pressure over a period of time. Data expressed as Mean (SD).

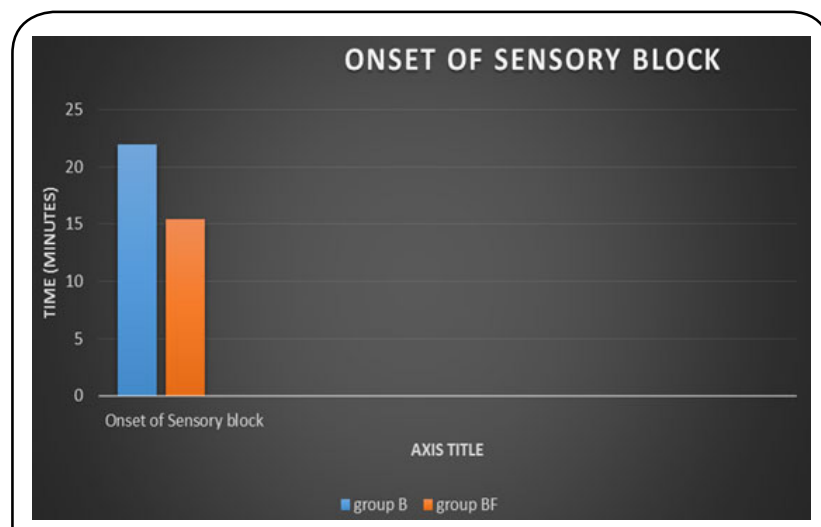

Figure 2. Onset of sensory block. Time ' 0 ' start after complete injection of drug in IPB. Data expressed as Mean (SD).

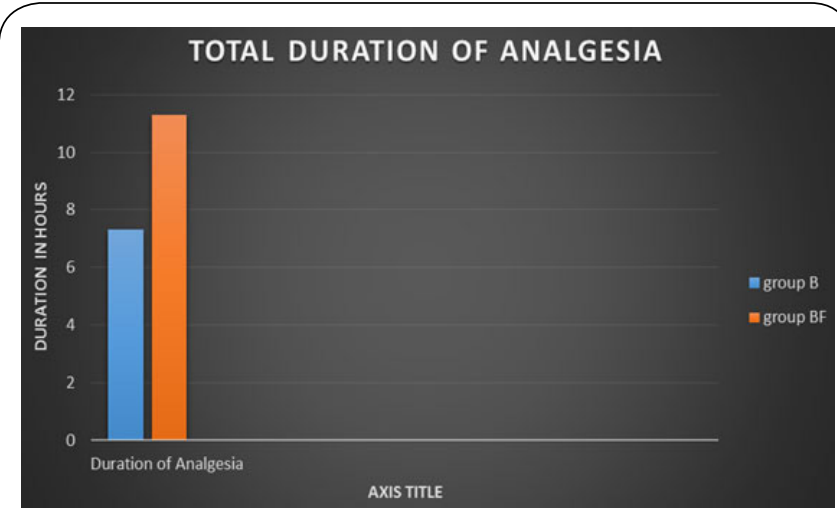

Figure 3. Total duration of analgesia. Time ' 0 ' start after complete injection of drug in IPB. Data expressed as Mean (SD).

Figure $4\{p<0.05\}$. Confidence interval of $95 \%$ cases of Group $B$ is 7.95 to 6.70 hours and Group BF is 11.61 to 10.99 hours.

Figures 5 and 6 shows mean VRS and VAS pain score in group $B$ and group $B F$ in postoperative period. There was no statistical significant difference in both the groups initially upto 240 minutes postoperatively. But after 240 minutes, the mean VRS and VAS score was consistently high in group $B$ than group BF which was statistically significant $\{p>0.05\}$, which shows that addition of fentanyl had prolonged the duration of analgesia beyond $240 \mathrm{~min}$.

More rescue analgesic doses required in group $B(3.025 \pm 0.69)$ than in group $B F(2.05 \pm 0.67)\{p<0.05\}$ (Figure 7).

Mean Peak Expiratory Flow Rate was comparable in both the groups preoperatively $\{p>0.05\}$. In postoperative period there was reduction in PEFR in both the groups in immediate postoperative period followed by gradual improvement in PEFR. The difference in both the groups was statistically not significant till 4 hrs postoperatively. But after $4 \mathrm{hr}$ postoperatively there was statistically significant difference in PEFR in both the groups $\{p<0.05\}$. More improvement in PEFR was noted in group $B F$, suggesting early improvement in PEFR than group B. We noticed nausea, vomiting, chest

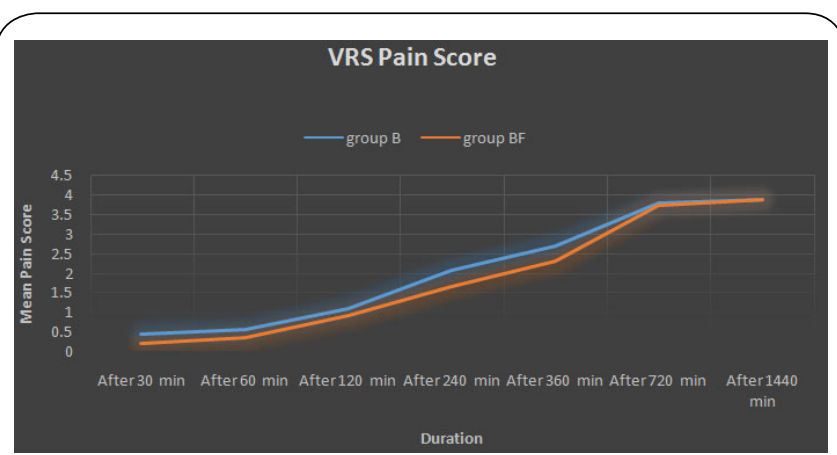

Figure 4. Changes in Verbal Response Scale pain score. Time ' 0 ' start postoperatively after shifting the patient in recovery area. Data expressed as Mean (SD). 


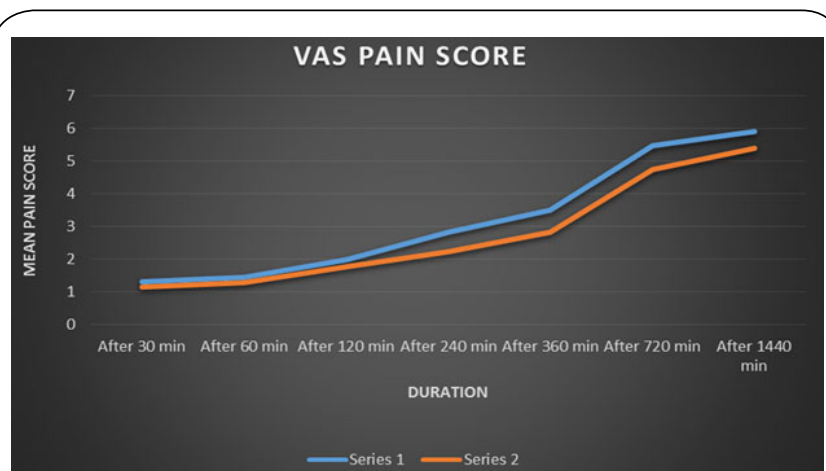

Figure 5. Changes in Visual Analog Scale pain score. Time '0' start postoperatively after shifting the patient in recovery area. Data expressed as Mean (SD).

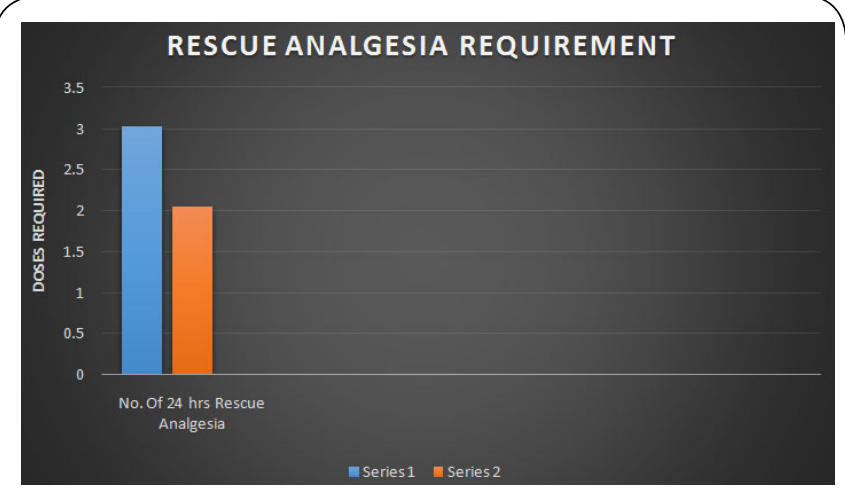

Figure 6. Rescue analgesics. Data expressed as Mean (SD).

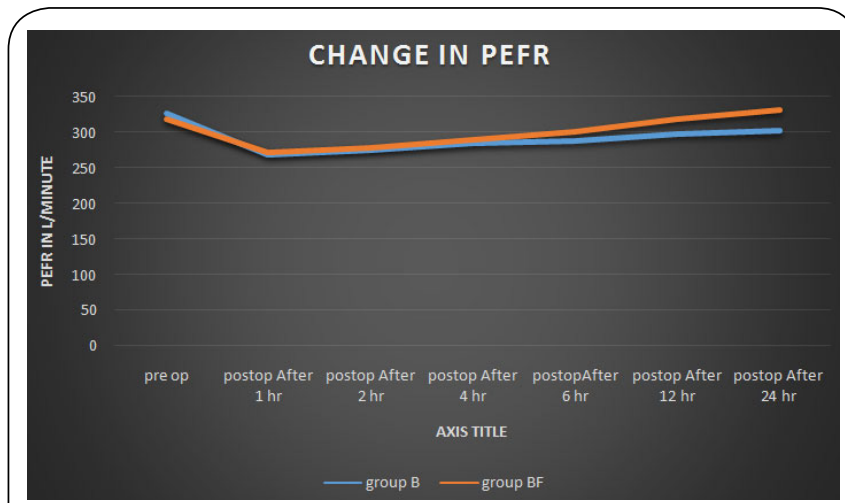

Figure 7. Changes in Peak expiratory flow rate over a period of time. Data expressed as Mean (SD).

pain, coughing during procedure, pruritus in patients of both the groups. There was no incidence of any intra-operative or post-operative complications like convulsion, hypotension, bradycardia, pneumothorax and respiratory depression.

\section{Discussion}

Intrapleural analgesia consists of the injection of a local anaesthetic into the pleural space. Intrapleural blockade is the technique of giving local anaesthetic in between two pleurae (parietal and visceral) to produce ipsilateral somatic block of various thoracic dermatomes. It also helps to reduce the pain by spread of local anaesthetic bilaterally to block both the splanchnic nerves and the sympathetic chains. It is effective in treating unilateral surgical as well as non-surgical pain from upper abdomen and chest in both the acute and chronic settings. Local anaesthetic solutions can be given as single or intermittent doses, or as continuous infusions via an indwelling intrapleural catheter.

Intrapleural analgesia has gained popularity because of its low rate of complications. Local anaesthetics as well as opioid agents administered via a catheter placed inside the pleural cavity have been used to anesthetize intercostal nerves to relieve pain.

Opioids administered by various routes are still the mainstay of analgesia for various upper abdomen surgeries pain management. However, systemic opioids have the potential for good pain relief at rest with a lack of effective pain reduction when coughing or breathing deeply. In addition, opioids may cause adverse effects such as respiratory depression, somnolence, prolonged nausea or vomiting and pruritus, when administered via a systemic or epidural route. Patients receiving epidural narcotics may also need care in a setting that monitors their respiration. Adverse effects seen with systemic and epidural opioids may be avoided when using opioids intrapleurally [11].

Various authors have observed that, addition of adjuvant to local anaesthetic for IPB not only provides excellent analgesia but also reduces the hemodynamic response to surgery and the intraoperative anaesthetics and analgesic requirements with better emergence from anaesthesia with fewer side effects, a prolonged pain-free period, improving the respiratory performance and giving a rapid mobilization and overall better quality of postoperative recovery which is essential in the reduction of immediate postoperative complications.

Early onset of analgesia by addition of fentanyl is also supported by a study done by B. Rastogi, M. Jain (2009) [12], where in a comparative clinical study of Intrapleural Bupivacaine And Intrapleural Bupivacaine With Morphine for Post-Operative analgesia for Laparoscopic Cholecystectomy ( $n=45)$, they have concluded that mean time of onset of analgesia was 30 min in B group and 15 min in group BM.

Prolongation of total duration of analgesia after addition of fentanyl in local anaesthetics is also suggested by Darshna D Patel, Varsha N Swadia [13] (2013) who studied "fentanyl versus sodium bicarbonate in axillary brachial plexus block" scheduled for elective hand and forearm orthopedic surgeries $(n=50)$ and concluded that, the duration of analgesia was $816.2 \pm 87.49$ minutes in Group F while it was $429 \pm 86.45$ minutes in Group SB, the $p$ value being $<0.001$ i.e. highly significant.

Sarita Gohiya and Vineet Gohiya [14] (2013) also concluded that, duration of analgesia is significantly prolonged after 
Ramteke et al. Journal of Anesthesiology \& Clinical Science 2019,

http://www.hoajonline.com/journals/pdf/2049-9752-8-1.pdf

doi: 10.7243/2049-9752-8-1

addition of fentanyl in bupivacaine for brachial block for upper limb surgeries (i.e. 11.45+/-1.50 hours in Group I and 21.9+/-2.25 hours in Group II).

There was no statistical significant difference in heart rate $(p>0.05)$ in both the groups throughout the procedure. It was noted that MAP was maintained at lower side in group BF throughout the procedure as compared to group $B$ though not statistically significant $(p>0.05)$. The reason for lower MAP could be the fentanyl induced hemodynamic stability. This findings are in agreement with findings of B. Rastogi, M. Jain [12] (2009), who studied effect of Intrapleural Bupivacaine and Intrapleural Bupivacaine with Morphine for Post-Operative analgesia for Laparoscopic Cholecystectomy. Their study also showed that the perioperative changes in hemodynamic parameters are non-significant in both the groups.

Mostafa Abdel Hamid Abo El Enin, Ismail Ewis Amin et al [15] (2009) in their study "Effect of Fentanyl Addition to Local Anaesthetic in Peribulbar Block" $(n=40)$ concluded that, addition of fentanyl to local anaesthetic mixtures improve quality of postoperative pain. There was statistically significant differences between the two groups as regard the median VAS at 1, 2, 3, 4, 5, 6 hours. Fentanyl group had lower median pain score than Control group.

B. Rastogi, M. Jain et al. [12] (2009), did a comparative clinical study of Intrapleural Bupivacaine And Intrapleural Bupivacaine With Morphine for Postoperative Analgesia for Laparoscopic Cholecystectomy. In their study, they noted that there was gradual improvement of PEFR in both the groups but that has no significant difference with bupivacaine alone group.

Shideh Dabir, MD, Tahereh Parsa, MD et al [11] (2008) findings are also in favour of our findings. In their study "Intrapleural Morphine vs Bupivacaine for Post thoracotomy Pain Relief" $(n=36)$ they came to the conclusion that, the number of patients who received intravenous morphine supplementation was significantly less in the morphine group than the bupivacaine group.

Complications in both the groups were statistically not significant, but few side effects specifically related to fentanyl, like pruritis was noted but needed no treatment, reassurance was sufficient. Bourke DL, Furman WR [16] (1993) studied, postoperative analgesia with morphine added to axillary block solution and concluded that, in study group where patients received morphine $0.1 \mathrm{mg} / \mathrm{kg}$ added to their axillary block solution, there were no major complications as compared to control group, who received saline added to their axillary block solution.

\section{Conclusion}

From this study we conclude that, when fentanyl was added as an adjuvant in intrapleural block, it fastens the onset of sensory block, prolongs duration of sensory bock, extends total duration of analgesia and has better preservation of respiratory functions compared to bupivacaine plus xylocaine-adrenaline alone. Intraoperatively hemodynamic stability was achieved in both the groups with no statistical significant difference in mean blood pressure and mean heart rate.

Competing interests

The authors declare that they have no competing interests.

Authors' contributions

\begin{tabular}{|l|c|c|c|c|}
\hline Authors' contributions & KPR & VAO & VSP & SP \\
\hline Research concept and design & $\checkmark$ & $\checkmark$ & $\checkmark$ & $\checkmark$ \\
\hline Collection and/or assembly of data & $\checkmark$ & $\checkmark$ & $\checkmark$ & $\checkmark$ \\
\hline Data analysis and interpretation & $\checkmark$ & $\checkmark$ & $\checkmark$ & $\checkmark$ \\
\hline Writing the article & $\checkmark$ & $\checkmark$ & $\checkmark$ & $\checkmark$ \\
\hline Critical revision of the article & $\checkmark$ & $\checkmark$ & $\checkmark$ & $\checkmark$ \\
\hline Final approval of article & $\checkmark$ & $\checkmark$ & $\checkmark$ & $\checkmark$ \\
\hline Statistical analysis & $\checkmark$ & $\checkmark$ & $\checkmark$ & $\checkmark$ \\
\hline
\end{tabular}

Acknowledgment

Thanks to the department of surgery, P. D. U medical college, Rajkot.

Publication history

EIC: D. John Doyle, Case Western Reserve University, USA.

Received: 07-Feb-2019 Final Revised: 01-April-2019

Accepted: 03-April-2019 Published: 02-May-2019

\section{References}

1. Michael A. E. Ramsay. Acute postoperative pain management. BUMC PROCEEDINGS. 2000; 13:244-247.

2. Klein SM, Bergh A, Steele SM, Georgiade GS and Greengrass RA. Thoracic paravertebral block for breast surgery. Anesth Analg. 2000; 90:1402-5. | Article I PubMed

3. Coveney E, Weltz CR, Greengrass R, Iglehart JD, Leight GS, Steele SM and Lyerly HK. Use of paravertebral block anesthesia in the surgical management of breast cancer: experience in 156 cases. Ann Surg. 1998; 227:496-501. | PubMed Abstract | PubMed FullText

4. Boughey JC, Goravanchi F, Parris RN, Kee SS, Kowalski AM, Frenzel JC, Bedrosian I, Meric-Bernstam F, Hunt KK, Ames FC, Kuerer HM and Lucci A. Prospective randomized trial of paravertebral block for patients undergoing breast cancer surgery. Am J Surg. 2009; 198:720-5. | Article | PubMed Abstract | PubMed FullText

5. Schnabel A, Reichl SU, Kranke P, Pogatzki-Zahn EM and Zahn PK. Efficacy and safety of paravertebral blocks in breast surgery: a meta-analysis of randomized controlled trials. Br J Anaesth. 2010; 105:842-52. | Article | PubMed

6. Richardson J, Sabanathan S, Mearns AJ, Shah RD and Goulden C. A prospective, randomized comparison of intrapleural and paravertebral analgesia in thoracic surgery. Br J Anaesth. 1995; 75:405-8.

7. Richardson J and Lonnqvist PA. Thoracic paravertebral block. $\mathrm{Br} J$ Anaesth. 1998; 81:230-8. | Pdf | PubMed

8. Klein SM, Bergh A, Steele SM, Georgiade GS and Greengrass RA. Thoracic paravertebral block for breast surgery. Anesth Analg. 2000; 90:1402-5. I Article | PubMed

9. Ballantyne JC, Carr DB, deFerranti S, Suarez T, Lau J, Chalmers TC, Angelillo IF and Mosteller F. The comparative effects of postoperative analgesic therapies on pulmonary outcome: cumulative meta-analyses of randomized, controlled trials. Anesth Analg. 1998; 86:598-612. | Article I PubMed

10. Reiestad F and Stromskug KE. Intrapleural catheter in the management of postoperative pain: a preliminary report. Regional Anaesthesia. 1986; 11:89-91.

11. Dabir S, Parsa T, Radpay B and Padyab M. Interpleural morphine vs bupivacaine for postthoracotomy pain relief. Asian Cardiovasc Thorac 
Ann. 2008; 16:370-4. | Article | PubMed

12. B Rastogi, $M$ Jain, $H$ Chauhan, D Singh and $Y$ Singh. A Comparative Clinical Study of Intrapleural Bupivacaine And Intrapleural Bupivacaine With Morphine for Post Operative Analgesia for Laparoscopic Cholecystectomy. The Internet Journal of Anaesthesiology. 2009; 27.

13. Darshna D Patel and Varsha N Swadia. Fentanyl Versus Sodium Bicarbonate In Axillary Brachial Plexus Block. Int J Res Med. 2013; 2:132136.

14. Sarita Gohiya and Vineet Gohiya. A Comparative study of efficacy of fentanyl added to Bupivacaine versus Bupivacaine alone used in supraclavicular brachial block for upper limb surgeries. Journal of pharmaceutical and biomedical sciences (J Pharm Biomed Sci.). 2013; 33:1573-1576.

15. Abo El Enin MA, Amin IE, Abd El Aziz AS, Mahdy MM and Mostafa MM. Effect of fentanyl addition to local anaesthetic in peribulbar block. Indian J Anaesth. 2009; 53:57-63. | Article | PubMed Abstract | PubMed FullText

16. Bourke DL and Furman WR. Improved postoperative analgesia with morphine added to axillary block solution. J Clin Anesth. 1993; 5:114-7. | Article | PubMed

\section{Citation:}

Ramteke KP, Oza VA, Parmar VS and Peram S.

Comparative study of bupivacaine plus xylocaine with adrenaline versus bupivacaine plus xylocaine with adrenaline plus fentanyl in intrapleural block for post operative analgesia for modified radical mastectomy cases. J Anesthesiol Clin Sci. 2019; 8:1.

http://dx.doi.org/10.7243/2049-9752-8-1 